\title{
A COMPARATIVE STUDY OF IONIC SILVER BASED DRESSINGS VERSUS CONVENTIONAL DRESSINGS IN MANAGEMENT OF DIABETIC FOOT ULCERS.
}

\section{General Surgery}

Dr. Ravishankar.N Professor, Department OfGeneral Surgery,jss Hospital, Mysuru.

\section{Dr. Shivakumar.S * $\begin{aligned} & \text { Associate Professor, Department Of General Surgery, Jss Hospital, Mysuru. } \\ & * \text { Corresponding Author }\end{aligned}$}

Dr. Abirami. K Junior Resident, Department Of General Surgery, Jss Hospital, Mysuru.

\section{ABSTRACT}

AIMS: To compare the efficacy of ionic silver-based dressings with conventional saline dressings in the management of diabetic foot ulcers. OBJECTIVES: To study the efficacy of ionic silver based amorphous hydrogel dressing containing colloidal silver in management of diabetic foot ulcer healing and to compare the time taken for wound healing, number of days taken to reach the end point and cost-effectiveness, with that of conventional saline dressings. METHODS: This was a case control, prospective, comparative study conducted in Department of Surgery, JSS Hospital, Mysuru. Totally 100 patients with diabetic foot ulcers were included, equally divided into -cases (received colloidal silver dressings) and controls (received saline dressings), Simple randomization was done. Study Duration- 18 Months. Data collected regarding changes in wound size, presence of granulation tissue, slough, presence or absence of discharge, was analysed - by Chi square test, Independent T test and Paired T test.RESULTS: There was significant percentage reduction in ulcer area, $66.76 \pm 16.8 \%$ in colloidal silver group, compared to only $\mathbf{2 . 7 1} \pm \mathbf{4 . 5 3} \%$ in conventional saline group. The number of days to end point was significantly lesser in colloidal silver group, compared to conventional group (23.16 $\pm \mathbf{8 . 1 6}$ days vs $48.34 \pm 18.06$ days), reduction of ulcer area (from $\mathbf{1 0 0 \%}$ ) was more at day $\mathbf{1 4}$ (48\% in silver group, $\mathbf{8 9 . 6 9 \%}$ in conventional group). CONCLUSION: The faster rate of wound healing in lesser number of days with significantly more reduction in ulcer area over a period of time, shows that ionic silver based amorphous hydrogel wound dressings with colloidal silver is more efficient than conventional saline dressings in diabetic foot ulcers management. As the number of dressings and number of days to end point is significantly lesser, ionic silver-based dressings are a comparatively more cost-effective treatment option as per our study.

\section{KEYWORDS}

Diabetic Foot Ulcer, Amorphous Hydrogel Wound Dressing, Colloidal Silver.

\section{INTRODUCTION:}

The prevalence of Diabetes Mellitus in India is more than $7.1 \%$ of the adult population with average age being 42.5 years. With such a high prevalence, the prevalence of Diabetic Foot Diseases (DFD) is high and also expected to increase in the future. Diabetic foot is one of the major complications of diabetes mellitus patients $15 \%$ diabetics develop foot ulcers during their lifetimes. If untreated they end up in lower extremity amputation. $85 \%$ of non-traumatic lower extremity amputations are due to diabetic foot. ${ }^{[1,2]}$ The management of diabetic ulcers requires a great degree of care as diabetic foot ulceration and infection are the main causes of hospitalization in diabetics. The choice of wound dressing plays a key role in the overall quality of life of the patient in terms of lesser morbidity, lesser duration of stay in the hospital, lesser expenditure for health care and most importantly the prevention of amputation of limb. With the right choice of wound dressing, up to $40 \%$ of amputations can be reduced. ${ }^{[3}$

The ideal wound dressing in diabetic foot ulcers should most importantly possess antimicrobial properties as the infection in diabetes extends into the deeper tissues, including bones with lesser clinical signs of inflammation. Silver dressings have been proved to possess anti-bacterial properties when used in wound dressings by studies in vitro and are effective against 150 micro-organisms, including yeasts. ${ }^{[4,5]}$ Colloidal Silver based dressing materials contain Silver nanoparticles - which expand the surface area of contact with the wound and also are in the ionic form $\mathrm{Ag}+$ cations which cause cell toxicity to bacteria - both gram positive and negative, including multi drug resistant strains and also promoting wound healing by the inhibition of MMPs( Matrix metalloproteinases) and are also effective against biofilms. ${ }^{[6,7]}$

\section{INCLUSION CRITERIA:}

- All patients above 18 years of age with Diabetes Mellitus.

- Patients with diabetic foot ulcers, post debridement.

- Size of the ulcer $>3 \times 3 \mathrm{~cm}$ and $<30 \times 30 \mathrm{~cm}$

\section{EXCLUSION CRITERIA:}

- Clinical evidence of active infection, osteomyelitis, septicemia.

- Diabetic ketoacidosis

- Significant systemic medical conditions that will impair wound healing - renal, hepatic, neurological, haematological disorders.

- General immunosuppressed conditions and states - patients receiving corticosteroids, radiation/chemotherapy 1 month prior to entry into the study

- Ulcers due to venous insufficiency.

Study Conduct:

- Alternate day dressings were performed for all patients in the ionic Silver based dressing group and the conventional dressing group.

- Ulcers were treated until the wound closed spontaneously or showed healthy granulation and was in a position to be grafted or secondarily sutured or until completion of the 8 weeks of assessment, whichever was earlier.

- Patients received supportive and conventional care of the wound throughout the study, including oral or injectable antibiotics.

- Blood sugar was controlled by insulin and oral hypoglycemics to be kept within acceptable levels for good control in diabetics.

- Wounds were assessed for: (a) Presence of wound discharge (b) Type of wound discharge (purulent/serous) (c) Granulation tissue (d) Changes in the size of wound (change in area) (e) Presence of slough (percentage of total surface area). Wound contraction and size were measured on day 1 and every 7days till discharge clinically by using surgical gauze and measuring tape.

\section{Study Treatment:}

Conventional dressing included Povidone-iodine wash followed by saline dressing as compared to the ionic Silver group where only saline followed by amorphous hydrogel wound dressing with

RESULTS: In our study, the mean age group in silver group was 62.4 years and in conventional group was 57.6 years, with more male than female patients in both groups. The distribution of ulcers based on etiology (spontaneous or post-traumatic), was comparable in both groups, with a $p$ value of 0.062 , statistically insignificant.

Table 1 - Number Of Dressings Required In Each Group

\begin{tabular}{|c|c|c|c|c|c|}
\hline \multirow{2}{*}{\multicolumn{2}{|c|}{}} & \multicolumn{4}{|c|}{ Dressing method } \\
\cline { 2 - 6 } \multicolumn{2}{|c|}{} & \multicolumn{3}{|c|}{\begin{tabular}{c} 
Colloidal Silver Dressing \\
\multicolumn{2}{|c|}{}
\end{tabular}} & \multicolumn{2}{c|}{$\begin{array}{c}\text { Conventional Saline } \\
\text { Dressing }\end{array}$} \\
\cline { 2 - 6 } & Count & Column N \% & Count & Column N \% \\
\hline Number & 1.0 & 50 & $100.0 \%$ & 41 & $82.0 \%$ \\
\cline { 2 - 6 } & 2.0 & 0 & $.0 \%$ & 4 & $8.0 \%$ \\
\cline { 2 - 6 } & 3.0 & 0 & $.0 \%$ & 4 & $8.0 \%$ \\
\cline { 2 - 6 } & 5.0 & 0 & $.0 \%$ & 1 & $2.0 \%$ \\
\cline { 2 - 6 } & Total & 50 & $100.0 \%$ & 50 & $100.0 \%$ \\
\hline
\end{tabular}

$\mathrm{P}=0.02$, chi square test 
In colloidal silver group, all (100\%) needed single dressing and in conventional group, $18 \%$ subjects needed multiple dressings, the average number of dressings (11.5) in Silver group was significantly lower than the conventional group (24.04), was statistically significant

Table 2 - Percentage Area Changes Over First And Second Week

\begin{tabular}{|c|c|c|c|c|c|}
\hline \multirow{2}{*}{} & \multicolumn{3}{|c|}{ Dressing method } & \multirow{2}{*}{ P } \\
\cline { 2 - 5 } & \multicolumn{3}{|c|}{$\begin{array}{c}\text { Colloidal } \\
\text { Silver Dressing }\end{array}$} & $\begin{array}{c}\text { Conventional Saline } \\
\text { Dressing }\end{array}$ & \multirow{2}{*}{} \\
\cline { 2 - 5 } & Mean & SD & Mean & SD & \\
\hline \% area by 7th day & 66.00 & 12.79 & 85.18 & 25.46 & $<0.0001$ \\
\hline$\%$ area by 14th day & 48.33 & 17.28 & 89.69 & 7.29 & $<0.0001$ \\
\hline $\begin{array}{c}\text { Area reduction } \\
\text { (Day1-Day14) }\end{array}$ & 24.35 & 24.47 & 5.04 & 4.47 & $<0.0001$ \\
\hline $\begin{array}{c}\text { Percentage reduction } \\
\text { area from Day1 }\end{array}$ & 66.76 & 16.81 & 22.71 & 24.53 & $<0.0001$ \\
\hline
\end{tabular}

There was significant reduction of area of ulcer to $66 \% \pm 12.79 \%$ in colloidal Silver group, compared to conventional group, $85.18 \pm 25.46 \%$ at day 7 and $48 \pm 17.28 \%$ in colloidal Silver group, compared to conventional $89.69 \pm 7.29$ at day14. The mean area reduced was significantly higher in colloidal Silver group, compared to conventional by day14 $\left(24 \pm 24.47 \mathrm{~cm}^{2}\right.$ vs $\left.5.04 \pm 4.47 \mathrm{~cm}^{2}\right)$. The percentage reduction in ulcer area was more, $66.76 \pm 16.8 \%$ in colloidal Silver group, compared to $22.71 \pm 4.53 \%$ in conventional group, was statistically significant. The number of days to end point was significantly lesser in colloidal Silver dressing group, compared to conventional dressing group (23.16 \pm 8.16 vs $48.34 \pm 18.06)$.

\section{GRAPH SHOWING CHANGE IN AREA OF ULCERS ON DAY} $1,7,14$

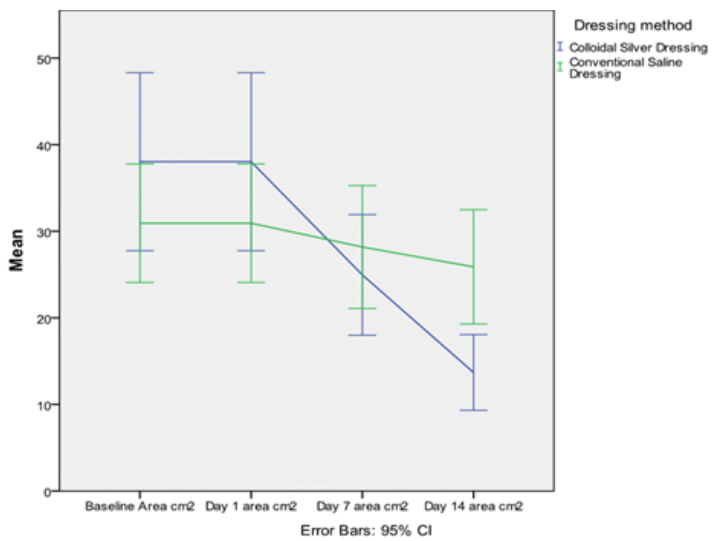

GRAPH SHOWING MEAN AREA REDUCTION FROM DAY 1 TO 14 IN THE STUDY POPULATION

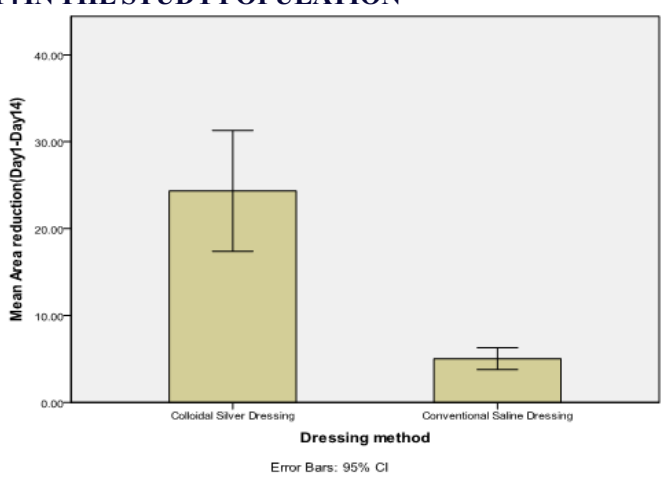

Table 3 - The Number Of Days To End Point And Number Of Dressings In Study Population.

\begin{tabular}{|c|c|c|c|c|c|c|c|c|c|c|}
\hline & \multicolumn{9}{|c|}{ Dressing method } & \\
\hline & \multicolumn{9}{|c|}{\begin{tabular}{l|l} 
Colloidal Silver Dressing & Conventional Saline Dressing \\
\end{tabular}} & \\
\hline & Median & Q1 & Q3 & Mean SD & Median & Q1 & Q3 & Mean & SD & $\mathrm{p}$ \\
\hline $\begin{array}{l}\text { Number } \\
\text { of days to } \\
\text { end point }\end{array}$ & 23.50 & 16.0 & 30.0 & 23.168 .16 & 48.50 & 41.0 & 58.0 & 48.34 & 18.06 & $\begin{array}{c}<0.000 \\
1\end{array}$ \\
\hline $\begin{array}{c}\text { Number } \\
\text { of } \\
\text { dressings }\end{array}$ & 11.50 & 8.0 & 15.0 & 11.504 .09 & 24.00 & 21.0 & 29.0 & 24.04 & 9.09 & $\begin{array}{c}<0.000 \\
1\end{array}$ \\
\hline
\end{tabular}

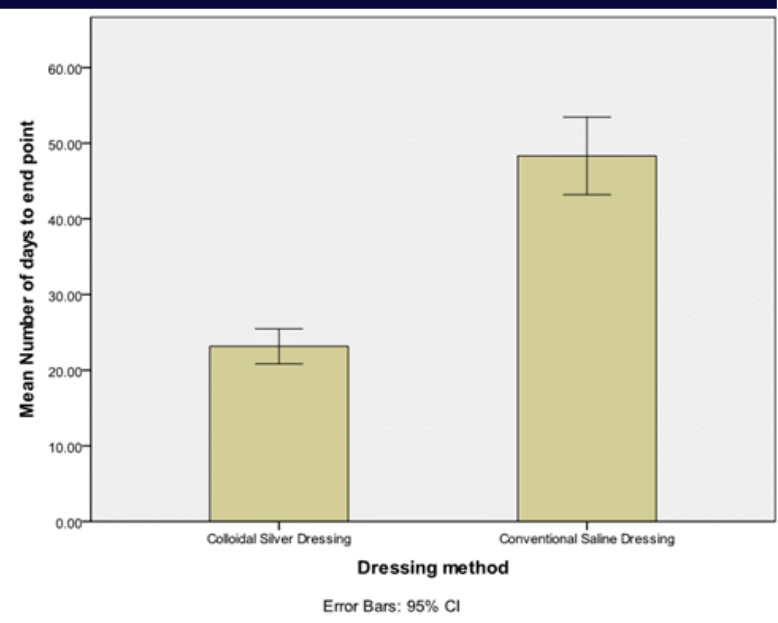

The number of days to end point in the Silver group was an average of 23.16 days, in the conventional group 48.34 days, the Silver group patients had a statistically significant lesser number of days to reach the end point.

Table - Progressive Evaluation Of Slough, Granulation, Discharge In Ulcers In The Study Population.

Granulation tissue formation and percentage reduction in slough and discharge was faster in silver group.

\begin{tabular}{|c|c|c|c|c|c|c|}
\hline & \multicolumn{4}{|c|}{ Dressing method } & \multirow[t]{3}{*}{$\mathrm{p}$} \\
\hline & & \multicolumn{2}{|c|}{$\begin{array}{l}\text { Colloidal Silver } \\
\text { Dressing }\end{array}$} & \multicolumn{2}{|c|}{\begin{tabular}{|c|} 
Conventional \\
Saline Dressing
\end{tabular}} & \\
\hline & & Count & $\underset{\%}{\text { Column } N}$ & Count & $\begin{array}{c}\text { Column } \\
\mathrm{N} \%\end{array}$ & \\
\hline Day 1 slough & & 31 & $62.0 \%$ & 47 & $94.0 \%$ & $<0.0001$ \\
\hline Day7 slough & & 20 & $40.0 \%$ & 28 & $56.0 \%$ & 0.03 \\
\hline \multirow[t]{2}{*}{ Day 14 slough } & & 7 & $14.0 \%$ & 12 & $24.0 \%$ & 0.2 \\
\hline & $\mathrm{p}$ & \multicolumn{2}{|c|}{$<0.0001$} & \multicolumn{2}{|c|}{$<0.0001$} & \\
\hline Day 1 discharge & & 39 & $78.0 \%$ & 50 & $100.0 \%$ & 0.002 \\
\hline Day 7 discharge & & 22 & $44.0 \%$ & 50 & $100.0 \%$ & $<0.0001$ \\
\hline \multirow[t]{2}{*}{ Day 14 discharge } & & 15 & $30.0 \%$ & 50 & $100.0 \%$ & $<0.0001$ \\
\hline & $\mathrm{p}$ & $<0.0001$ & $<0.0001$ & & & \\
\hline Day 1 Granulation & & 0 & $.0 \%$ & 3 & $6.0 \%$ & 0.08 \\
\hline Day 7 granulation & & 47 & $94.0 \%$ & 26 & $52.0 \%$ & $<0.0001$ \\
\hline \multirow[t]{2}{*}{ Day 14 granulation } & & 49 & $98.0 \%$ & 49 & $98.0 \%$ & 1 \\
\hline & $\mathrm{p}$ & \multicolumn{2}{|c|}{$<0.0001$} & \multicolumn{2}{|c|}{$<0.0001$} & \\
\hline
\end{tabular}

\section{DISCUSSION:}

It is safe to say that Diabetic foot ulcers are the most common form of chronic non- healing ulcers of foot encountered in clinical practice with close to $70 \%$ of the patients requiring surgical intervention and $40 \%$ of the patients landing up with an amputation and there is still no consensus in the medical field regarding the best mode of treatment for diabetic foot ulcers. With such a wide prevalence of diabetic foot ulcers responsible for the huge burden of morbidity among diabetics and extensive knowledge about the disease process in diabetics, the question of whether the use of conventional dressings is acceptable as the standard of care for diabetic foot ulcers at this point of time, with a number of modern biological dressings that are available.

Although Silver has been a known adjuvant in wound healing, it has been largely used in the management of burns, more than diabetic foot wounds. With the application of nanotechnology to the wound healing properties of Silver, colloidal Silver based dressings with ionic silver ions as active component have been developed and widely available across countries as bio active dressings. The benefits of this preparation being almost nil or negligible systemic toxicity compared to older topical Silver preparations.

The reason for this being, smaller size of particles which cover an increased surface area, the particles eluting the Silver ions at a rate much lower than that required to cause systemic toxicity. Studies have proven that silver is effective against biofilms formed by microbes, which are generally resistant to topical adjuvants used in wound management, due to their inherent barrier mechanism. When silver 
ions are delivered at a sustained as well as optimum concentration, that is , more than $30 \mathrm{ppm}$, to have anti biofilm properties, less than $60 \mathrm{ppm}$ to have no systemic effects, which is achieved by colloidal silver based preparations, that act as a depot for silver ions, maintaining optimum ionic silver concentration for prolonged periods of time. Hence, a sustained local antimicrobial effect, brought about by the colloidal silver which acts as a silver ion depot, as well as adequate moisture, absorption of excess exudate, preventing microbial colonization and also relatively painless while removing the dressing, which are all the properties of the amorphous hydrogel dressing, provides an environment that favours wound healing is, which is the ultimate aim of any dressing.

In our study, multiple factors were considered to compare the efficacy of ionic Silver based dressings with conventional dressings in the management of diabetic foot ulcers. Based on the results of our study, there was significant reduction of area of ulcer to $66 \%$ (compared to initial area-100\%) in colloidal Silver dressing group, compared to conventional dressing $85.18 \%$ at day 7 and significant reduction of area of ulcer to $48 \%$ in colloidal Silver dressing group, compared to conventional dressing $89.69 \%$ at day 14 . On the same line, the number of days to end point, that is spontaneous closure or ulcer fit for split thickness skin grafting, was significantly lesser in colloidal Silver dressing group, compared to conventional dressing group (23.16 \pm 8.16 days vs $48.34 \pm 18.06$ days) which is a significant difference. Also, the total number of dressings required till the end point was significantly lesser compared to that of conventional dressing group. Although there was no statistically significant difference in the duration of stay in the hospital, it is safe to say that it cannot make a difference in evaluating the ultimate efficacy of the dressing material, as the reason for stay in the hospital is a multifactorial one, influenced by co-morbid conditions of the patient, patient factors like patients requesting to stay in the hospital for few extra days in view of alternate day dressings.

\section{CONCLUSION:}

Ionic Silver based amorphous hydrogel wound dressings are being used widely in the management of burn wounds, not so widely used in diabetic foot ulcers. While comparing them with conventional saline dressings, that are most commonly used in diabetic foot ulcers, we found that ionic Silver based dressings have a faster rate of wound healing, evident by early appearance of granulation tissue, degree of response to the treatment at the end of 2 weeks, decrease in percentage of slough and discharge, effective decrease in the percentage of ulcer area, compared to conventional dressings. Also, the patients in our study group, who received ionic Silver based dressings, required lesser number of days to reach the end point and had either spontaneous closure of ulcer or were ready for a split thickness skin graft. The Silver group patients also required significantly lesser number of dressings compared to that of conventional group. Hence, we conclude from our study that, ionic Silver based dressings are clearly a superior method of treatment for diabetic foot ulcers, while also being a cost effective option for the patients and we suggest that it be strongly considered to make them the standard of care for diabetic foot ulcer management.

\section{RECOMMENDATIONS:}

As per the results of our study, amorphous hydrogel wound dressings containing colloidal Silver have been found to be superior to conventional saline dressings in the management of diabetic foot ulcers, with no adverse effects.

\section{LIMITATIONS:}

The study population was a total of 100 patients, 50 cases and 50 controls, which is a small sample size in consideration with the general population, which is the major limitation of our study. There were no parameters assessed to look for systemic absorption of Silver, although the concentration was well within levels of toxicity.

\section{REFERENCES:}

1. Gupta, V., Kakkar, G., Gill, A. S., Gill, C. S., \& Gupta, M. (2018). Comparative Study of Nanocrystalline Silver Ion Dressings with Normal Saline Dressings in Diabetic Foot Ulcers. Journal of Clinical \& Diagnostic Research, 12(6).

2. Sharma, R., Gupta, N., Kumar, V., Pal, S., Kaundal, V., \& Sharma, V. (2017). Silver colloid dressings score over conventional dressings in diabetic foot ulcer: a randomized clinical trial. International Surgery Journal, 4(8), 2627-2631

3. Ramanaiah, N. V., Saikrishna, C., Vamshidhar G. V. \& Lokesh, K. (2015). A clinical study on efficacy of nanocrystalline silver dressing in diabetic foot ulcers. J Evid Based study on efficacy of nanocrystalline

4. Konop, M., Damps, T., Misicka, A., \& Rudnicka, L. (2016). Certain aspects of silver and silver nanoparticles in wound care: a minireview. Journal of Nanomaterials, 2016.

5. Lin, Y. H., Hsu, W. S., Chung, W. Y., Ko, T. H., \& Lin, J. H. (2016). Silver- based wound dressings reduce bacterial burden and promote wound healing. International wound journal, 13(4), 505-511.

6. Murphy, P. S., \& Evans, G. R. (2012). Advances in wound healing: a review of curren wound healing products. Plastic surgery international, 2012

7. Warriner, R., \& Burrell, R. (2005). Infection and the chronic wound: a focus on silver. Advances in skin \& wound care, $18(8), 2-12$ 